\title{
Clinical predictors and radiological reliability in atlantoaxial subluxation in Down's syndrome
}

\author{
K A Selby, R W Newton, S Gupta, L Hunt
}

\begin{abstract}
Clinical signs and symptoms that might predict atlantoaxial subluxation were studied prospectively in 135 of 180 children with Down's syndrome aged 6-14 years who form the Hester Adrian Research Centre cohort. Lateral radiographs of the cervical spine were taken in flexed, extended, and neutral positions, and the percentage of abnormalities in each view was 14,10 , and $10 \%$, respectively. Gait was the only significant clinical predictor. The relative risk of having an abnormal neck radiograph with an abnormal gait was 2.91 (95\% confidence interval (CI) 1 to 8). The sensitivity was $50 \%$ and the specificity $81 \%$. Nineteen children had repeat radiographs to assess the reliability of radiological diagnosis. Six had abnormalities; five of $19(26 \%)$ had an abnormality on the first radiograph, and four of $19(21 \%)$ had an abnormality on a second radiograph, but only three $(15 \%)$ had an abnormality on both occasions in any view (95\% CI 0 to 25).

We conclude that radiographs of the cervical spine are unreliable at identifying atlantoaxial subluxation in children with Down's syndrome, and we failed to identify any reliable clinical predictor.
\end{abstract}

Atlantoaxial subluxation has been reported to occur in $9 \cdot 5-27 \%$ of individuals with Down's syndrome, ${ }^{1-46}$ although symptomatic dislocation has rarely been reported. The association of atlantoaxial subluxation with Down's syndrome was noted in the 1960s when Spitzer et al described forward displacement of the atlas on the axis. ${ }^{7}$ Atlantoaxial subluxation may be a manifestation of hypotonia and joint laxity that occurs in children with Down's syndrome allowing increased mobility between the atlas and the axis during flexion and extension of the neck. Abnormalities of the odontoid process of the axis may also play a part. ${ }^{8}$ When atlantoaxial subluxation occurs it may also cause compression of the spinal cord. The incidence has been reported as $1.5 \%$ in an unselected study on 404 individuals with Down's syndrome. ${ }^{6}$

Previous studies have reported on hospital based populations, and the incidence of abnormality may therefore be artificially high. A recent community based study of adults sought a correlation between radiological and neurological abnormality. ${ }^{9}$ The neurological testing was, however, less detailed and less sensitive than in the present study. Furthermore, to reflect the underlying improvement of atlantoaxial subluxation with age a stricter definition was used (atlantodens distance $>3 \mathrm{~mm}$ ).
We chose to study a population based group that had already been validated as a cohort. We hoped to identify simple clinical parameters that could be used by senior clinical medical officers to identify the problem within the community. No previous studies to our knowledge have prospectively sought predictive signs.

In 1984 the Committee on Sports Medicine of the American Academy of Pediatrics published recommendations that all patients with Down's syndrome who wished to take part in sports involving stress on the head and neck in the special Olympic games should have a medical examination, and radiographs of the cervical spine taken in full flexion and extension, to ensure that there was no evidence of atlantoaxial subluxation or neurological abnormality. If these were both normal at 5-6 years of age no further follow up would be required. ${ }^{11}$

In Britain these recommendations were supported by the Department of Health and by Mencap, ${ }^{12}$ and so a radiograph of the neck indicating an abnormality led to restriction of active sports such as gymnastics, trampolining and diving, and to referral for neurological assessment.

\section{Patients and methods}

Between August 1973 and August 1980 the Hester Adrian Research Centre (HARC) recruited a cohort of children with Down's syndrome in the Greater Manchester area. They were referred by general practitioners, paediatricians, and health visitors. All diagnoses were confirmed by chromosomal analysis. The validity of this cohort was confirmed by notifications of Down's syndrome to the Office of Population Censuses and Surveys and from records at the regional cytogenetics laboratory. ${ }^{14}$

Of the 180 children in the cohort, 135 were admitted to the present study, 19 of the nonparticipants had died, 17 had moved from the area, and parental consent was refused in nine.

The children were aged between 6-14 years at the time of the study, mean $9 \cdot 3$ years. Ethics committee approval was granted. Informed consent was obtained and, for those families who agreed to take part, a letter was sent from the regional department of child and adolescent neurology to arrange a consultation. All the children were examined by one paediatrician (KAS) and the clinical findings were kept from the clinician interpreting the radiographs. The families were interviewed and a questionnaire with symptoms relating to neck stiffness, bowel and bladder control, toe walking, and sleep apnoea was discussed. Motor skills were assessed by the modified Gubbay test, ${ }^{15}$ 
which consists of four independent tests scored against standardised norms for both normal children and children with moderate learning difficulties. ${ }^{16}$

Further assessments of hand and leg function and of gait were made with the quick neurological screening test. ${ }^{17}$ Neurological examination included assessment of power, tone, reflexes, clonus, gait, and neck movements. The scoring of gait paid particular attention to eversion of the feet, abnormality of heel-toe placing, and fluency of movement.

The children then had radiographs of the cervical spine taken in flexed, extended, and neutral positions. Atlantoaxial distance was defined as the measurement from the posteroinferior aspect of the anterior arch of the atlas to the anterior surface of the odontoid process and was regarded as abnormal if it was $>4.5 \mathrm{~mm}$. All radiographs were reported by one consultant paediatric radiologist who was unaware of the clinical findings.

During the study, it was noted that a second radiograph of a child failed to show a previously observed abnormality. After this, the remaining 19 children in the study had repeat radiographs taken (with informed parental consent) after a 10 minute interval to indicate the degree of reliability.

The $\chi^{2}$ test with Yates's correction was used to assess the significance of differences between groups, and a $p$ value of $<0.05$ was accepted as significant. Relative risks and $95 \%$ confidence intervals $(\mathrm{CI})$ were calculated.

Table 1 Abnormality (atlantoaxial distance $>4.5$ mm) shown on radiographs of the cervical spine in 19/135 patients

\begin{tabular}{ll}
\hline Position & $\begin{array}{l}\text { No(\%) } \\
\text { with } \\
\text { abnormality }\end{array}$ \\
\hline $\begin{array}{c}\text { Flexion } \\
(\mathrm{n}=124)\end{array}$ & $18(15)$ \\
$\begin{array}{c}\text { Extension } \\
(\mathrm{n}=122)\end{array}$ & $12(10)$ \\
$\begin{array}{c}\text { Neutral } \\
(\mathrm{n}=112)\end{array}$ & $11(10)$ \\
\hline
\end{tabular}

\section{Results}

RADIOGRAPHS OF THE CERVICAL SPINE (table 1) Most abnormalities were found in flexion, which identified $95 \%$ of patients with atlantoaxial subluxation.

\section{NEUROLOGICAL ASSESSMENT (table 2)}

Significantly more children with an abnormal gait had abnormal radiographs (nine of $30 \mathrm{com}$ pared with nine of $101, \mathrm{p}<0.01$ ). The relative risk of an abnormal radiograph of the neck occurring in a patient with an abnormal gait is $2.91 \mathrm{p}<0.05,95 \%$ CI 1 to 8 ). No other significant correlations were found. The gait measurements in the quick neurological screening test showed a positive but not significant correlation with abnormal radiographs of the neck $(p=0 \cdot 2)$. The sensitivity of gait as a measure of atlantoaxial subluxation was $50 \%$ and the specificity $81 \%$.

The sequential set of results shown in table 3 are those of case 80 , a 10 year old boy with evidence of toe walking. A further 18 children also

Table 2 Correlation of radiographic appearance and gait in 131 children with Down's syndrome

\begin{tabular}{lllr}
\hline Gait & Radiographs & Total \\
\cline { 2 - 3 } & $\begin{array}{l}\text { No(\%) } \\
\text { normal }\end{array}$ & $\begin{array}{l}\text { No(\%) } \\
\text { abnormal }\end{array}$ & \\
\hline $\begin{array}{lllr}\text { Normal } \\
\text { Abnormal }\end{array}$ & $\begin{array}{l}92(91) \\
21(70)\end{array}$ & $\begin{array}{l}9(9) \\
9(30)\end{array}$ & $\begin{array}{r}101 \\
\end{array}$ \\
\hline
\end{tabular}

Four children with abnormal gait did not have radiographs Four chill
taken.
Table 3 Atlantoaxial distance $(\mathrm{mm})$ in three sets of radiographs on one patient

\begin{tabular}{llll}
\hline Position & Radiograph & & \\
\cline { 2 - 4 } & 1 & 2 & 3 \\
\hline Flexion & 10 & 6 & 3 \\
Extension & 3 & 4 & 3 \\
Neutral & 12 & 2 & 5 \\
\hline
\end{tabular}

Interval between radiographs 1 and 2 was three weeks and between radiographs 2 and 3 was 10 minutes.

Table 4 Atlantoaxial distances ( $\mathrm{mm}$ ) on two sets of radiographs taken 10 minutes apart from six of 19 children with radiographic abnormalities

\begin{tabular}{|c|c|c|c|c|c|c|}
\hline \multirow{3}{*}{$\begin{array}{l}\text { Case } \\
\text { No }\end{array}$} & \multicolumn{6}{|l|}{ Position } \\
\hline & \multicolumn{2}{|l|}{ Neutral } & \multicolumn{2}{|c|}{ Flexion } & \multicolumn{2}{|c|}{ Extension } \\
\hline & First & Second & First & Second & First & Second \\
\hline $\begin{array}{l}1 \\
2\end{array}$ & $\begin{array}{l}\text { Not } \\
\text { recorded } \\
\text { Not }\end{array}$ & 4 & 2 & 5 & 4 & 3 \\
\hline $\begin{array}{l}3 \\
3 \\
4 \\
5 \\
6\end{array}$ & $\begin{array}{c}\text { recorded } \\
4 \cdot 5 \\
3 \\
5 \\
12\end{array}$ & $\begin{array}{l}2 \\
4 \cdot 5 \\
3 \\
3 \\
2\end{array}$ & $\begin{array}{r}7 \\
4 \\
3 \\
5 \\
10\end{array}$ & $\begin{array}{l}3 \\
4 \\
5 \\
3 \\
6\end{array}$ & $\begin{array}{l}4 \cdot 5 \\
3 \\
5 \\
5 \\
3\end{array}$ & $\begin{array}{l}3 \\
3 \\
5 \\
2 \cdot 5 \\
4\end{array}$ \\
\hline
\end{tabular}

had repeat radiographs. Of these 19 children (table 4) six (32\%) showed an abnormality. In five this was in the first set of films, in four in the second, and in three in both sets. Only one of three (case 3 ) in the neutral position was recorded as abnormal in both radiographs. One of five (case 6) remained abnormal in flexion, and one of three (case 4) remained abnormal in extension.

\section{Discussion}

The high incidence of atlantoaxial subluxation in Down's syndrome has been widely reported, ${ }^{1-10}$ and our incidence of $14 \%$ is in keeping with those results. Abnormalities of the odontoid process including hypoplasia and accessory odontoid ossicles have been reported relatively frequently in other studies. ${ }^{8}$ The methods on which the radiographic abnormalities are based refer almost exclusively to the adult population, and as the odontoid peg .(which has four ossification centres that ossify at various stages and then fuse together) does not attain its normal size and shape until at least 8-10 years of age, it will look relatively 'hypoplastic' in normal children. We did not identify any specific abnormality of the odontoid peg.

This study was carried out in a cohort of children with Down's syndrome. To our knowledge this is the first such study, and as it is a population based study it is reliable.

Radiographs of the neck seem to be unreliable in identifying atlantoaxial subluxation (the observed $14 \%$ abnormality had a $95 \%$ CI of 0 to $25)$. The reason for the variability may be due to ligamentous laxity; it cannot be due to upper respiratory tract infections ${ }^{20}$ or any other anomaly of the cervical vertebrae. ${ }^{8}$

Subjective observers have noted alterations in muscle tone with mood in children with Down's syndrome (hypotonic when subdued compared with relatively normal when angry or excited), and this may contribute to the lack of reliability of radiographs. 
Almost all the cases of atlantoaxial dislocation that have been reported were preceded by abnormal neurological symptoms and signs, ${ }^{18} 19$ and Pueschel found a $1.5 \%$ incidence of neurological signs with neck abnormalities. ${ }^{5}$ All the children in our study with radiographic abnormalities were asymptomatic with no neurological signs.

We attempted to assess predictive signs of atlantoaxial subluxation-objective measurements of gait abnormalities were not significantly associated with neck abnormalities. Further study of qualitative measures of gait in community based paediatric practice would be of value.

As radiographs of the neck are unreliable at identifying atlantoaxial subluxation we cannot recommend them for screening. Although the sensitivity of gait abnormality with a neck radiograph abnormality was $50 \%$ this may not be the result of pyramidal tract dysfunction, but of the hypotonia seen in the neck and feet of children with Down's syndrome.

Bearing in mind the extreme rarity of cord compression reported in the world literature, and given the poor reliability and reproducibility of abnormal radiography of the neck, we think that many children with Down's syndrome are having their lives unnecessarily restricted by defensive medical practice. Our findings would support the view of a re-examination of the evidence reported by Davidson in $1988 .{ }^{21} \mathrm{He}$, together with Roy et al, stated that the widespread implication of screening would deprive individuals with Down's syndrome from beneficial activities. In view of the above findings we feel that the advice given by Department of Health should be revised.

We thank Professor Cliff Cunningham for his advice and support and for information about the original cohort.
1 Pueschel SM, Scola FH. Epidemiological radiographic and clinical studies of atlantoaxial instability in individuals with
Down's syndrome. Pediatrics 1987;80:555-60.

2 Pueschel SM, Scola FH, Perry CD, et al. Atlantoaxial instability in children with Down's syndrome. Pediatr Radio 1981;10:129-32.

3 Martel W, Tischler JM. Observation on the spine in mongolism. AYR 1966;94:630-8.

4 Tischler JM, Martel W. Dislocation of the atlas in mongolism. Preliminary report. Radiology 1965;84:904-6.

5 Pueschel SM. Atlantoaxial subluxation in Down's syndrome. Lancet 1983;i:980.

6 Pueschel SM. Atlanto-axial instability. Sport and Down's syndrome. Lancet 1989;i:438-9.

7 Spitzer R, Rabinovitch JY, Wyber KC. A study of abnormalities of the skull, teeth and lenses in mongolism. Can Med Assoc I 1961;84:567-72.

8 Elliott S, Morton RE, Whitelaw RAJ. Atlantoaxial instability and abnormalities of the odontoid in Down's syndrome. and abnormalities of the odonto

9 Roy M, Baxter M, Roy A. Atlanto instability in Down's syndrome-guidelines for screening and detection. $\mathcal{f} R$ Soc syndrome-guidelines

10 Semine AA, Ertel AN, Goldberg MJ, Bull MJ. Cervical spine instability in children with Down's syndrome. $\mathcal{F}$ Bone foin Surg $[A m]$ 1978;60:649-52.

11 American Academy of Pediatrics. Committee on sports medicine. Atlantoaxial instability in Down's syndrome. Pediatrics 1984;74:152-4.

12 Acheson ED. Atlantoaxial instability in people with Down' syndrome. London: DHSS, 1986. (CMO (86) 8.)

13 Royal Society for Mentally Handicapped Adults and Children. Look before you leap. Sports and people with Down's syndrome. London: Mencap, 1985.

14 Cunningham C. Early support and intervention. The Hester Adrian Research Centre infant project. In: Mittler PJ, McConachie HR, eds. Parents, professionals and mentally Mandicapped people: approaches to partnership. London: handicapped people:

15 Gubbay SS. The mangement of developmental apraxia. Dev Med Child Neurol 1978;20:643-6.

16 McKinlay I, Bradley G, Hindle A, Ehrhardt P. Motor coordination of children with mild mental handicap. Up Med Sci 1987;(suppl):127.

17 Mutti M, Sterling HM, Spalding NV. Quick neurological screening test-revised edition. Academic therapeutic publication. San Jose: State University, 1978.

18 Choudry V, Sturgeon C, Gates AJ. Symptomatic atlantoaxia dislocation in Down's syndrome. Ann Neurol 1978;21: 606-9.

19 Hungerford GD, Akkaraya V, Rowe SE, Young GF. Atlantooccipital and atlantoaxial dislocation with spinal cord compression. A case report and review of the literature. $B$ f Radiol 1981;54:758-61.

20 Coria F, Quintana F, Villaba M. Craniocervical abnormalities in Down's syndrome. Dev Med Child Neurol 1983;25: in D2-5.

21 Davidson RG. Atlantoaxial instability in individuals with Down's syndrome: a fresh look at the evidence. Pediatrics 1988;81:857-65. 